\title{
Adenosis (Atypical Adenomatous Hyperplasia) of Prostate
}

\section{Dilek Ertoy Baydar}

Hacettepe University Faculty of Medicine, Department of Pathology, Ankara, Turkey

Adenosis is one of the most common pseudoneoplastic lesions in the prostate that may be confused with adenocarcinoma because of its cytologic and architectural features (1). Another commonly used term for adenosis is atypical adenomatous hyperplasia.

It almost exclusively develops in the transition zone often within or adjacent to typical hyperplastic nodules and often multifocal. The prevalence of adenosis in transurethral prostatectomy specimens without cancer ranges from $1.6 \%$ to $7.3 \%$ (2). It has been detected in up to $33 \%$ of radical prostatectomy specimens (3). Due to uncommon sampling of the transition zone, it is rare in transrectal needle biopsies of the prostate, having a prevalence of around $0.8 \%$ (4).

Microscopically, adenosis is a localized proliferative lesion consisting of closely packed but separate glands without evidence of fusion (Figure 1). Under low power, it is usually circumscribed with a pushing rather than infiltrating border, although the small acini may show a limited degree of infiltrative features at the margins.

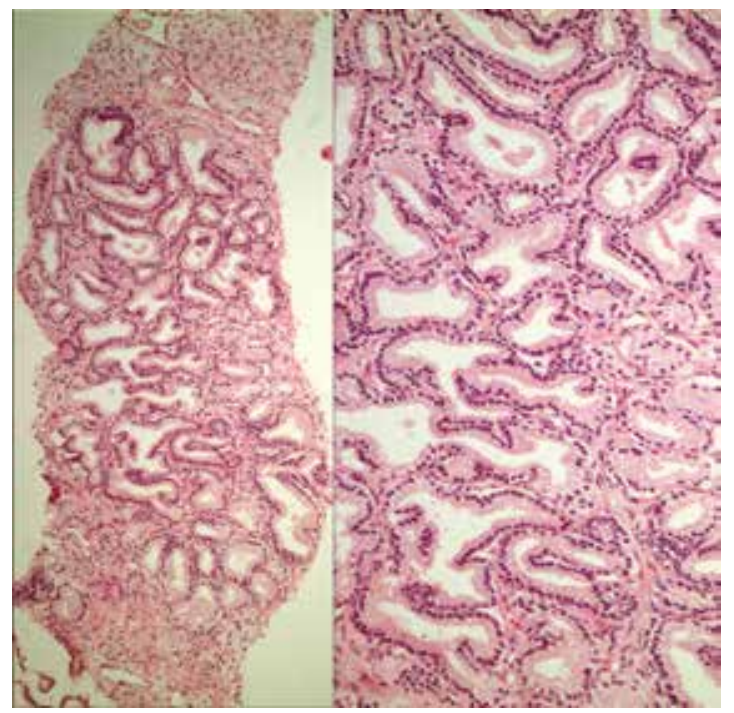

Figure 1. 59-year-old male who had undergone transrectal prostatic needle biopsy was referred to our department after a diagnosis of ASAP (atypical small acinar proliferation) with suspicion of malignancy in one of the 12 cores by the original pathology center. The microscopical examination revealed a group of crowded glands composed medium to small sized prostatic acini with little intervening stroma
The glands may show some variation in size and shape. The lining cells are cuboidal to low columnar, having moderate to abundant clear or lightly eosinophilic cytoplasm (Figure 2). The basal cells can usually be recognized at least focally (Figure 3). The luminal borders of the glands are often irregular with papillary infoldings and branching lumina (Figure 4). This contrasts with the rigid sharp borders that characterize small acinar carcinoma. The lumina can be empty though corpora amylacea are commonly seen in adenosis. Some cases (18-39\% of foci of adenosis) may contain intraluminal eosinophilic crystalloids. The nuclei are bland, round to oval, and can be slightly enlarged. Nucleoli are either inconspicuous or small. Yet, fairly prominent (>1.6 microns) nucleoli have been reported in as many as $40 \%$ of cases. But huge nucleoli ( $>3$ microns) are incompatible with a diagnosis of adenosis. There is usually no stromal reaction but occasionally, a fibroblastic response is identified which leads to similarity with the pattern of sclerosing adenosis.

Adenosis is sometimes a difficult entity to discriminate from low-grade prostatic adenocarcinoma (Gleason pattern 1 or 2).

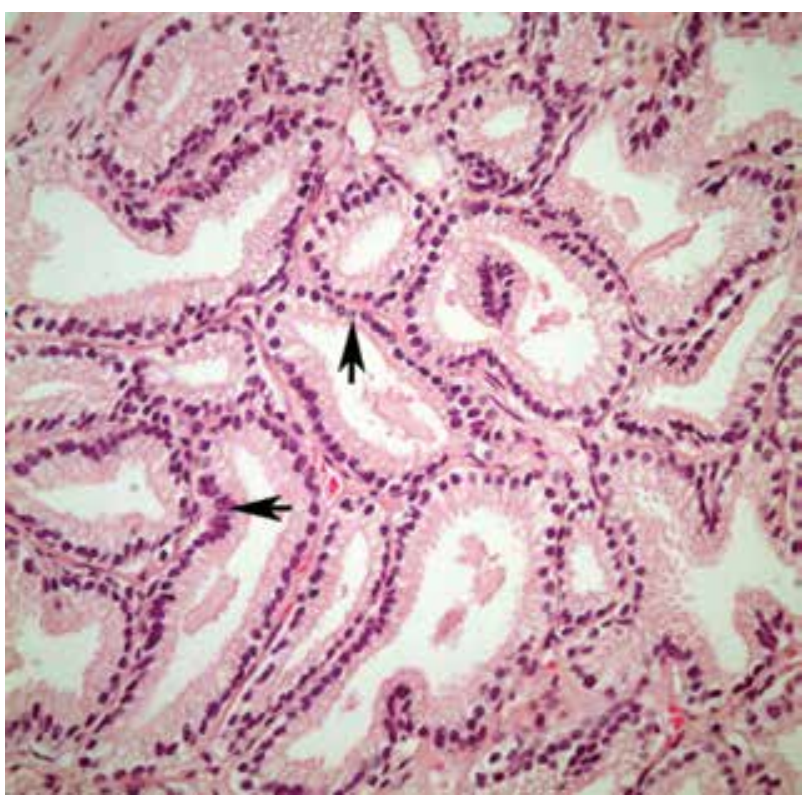

Figure 2. The acini were lined by uniform cuboidal or columnar cells with clear cytoplasm. Their nuclei were mildly enlarged, but nucleoli were generally small. Only rarely prominent nucleoli were identified (arrows)

\section{Correspondence}

Dilek Ertoy Baydar MD, Hacettepe University Faculty of Medicine, Department of Pathology, Ankara, Turkey

E-mail: dilekertoy@yahoo.com 


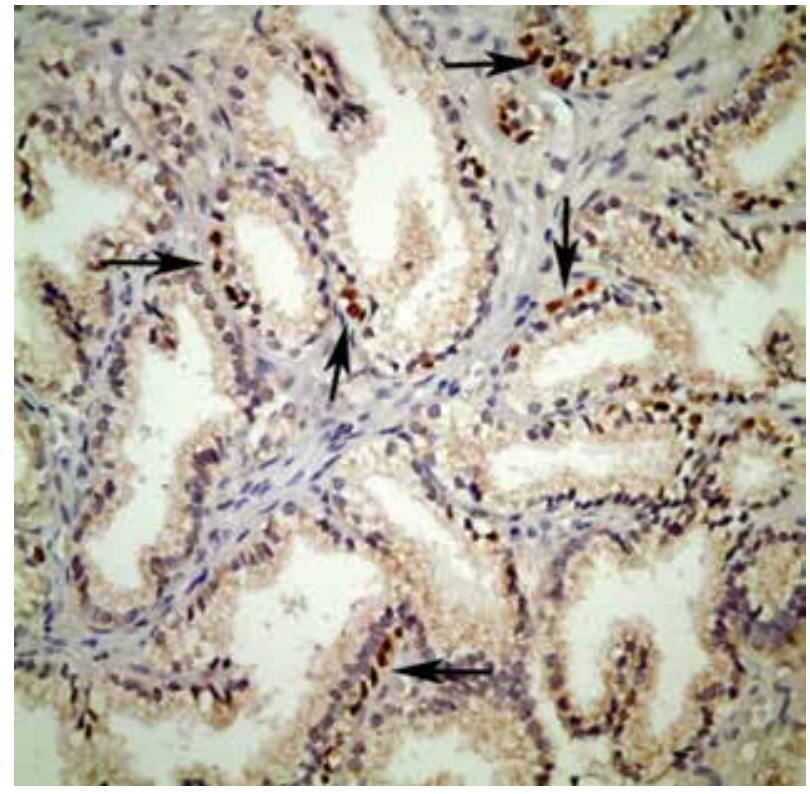

Figure 3. Immunohistochemistry for p63 (a basal cell specific immunostain) showed the presence of basal cells around suspicious glands (arrows). This finding ruled out prostatic adenocarcinoma and confirmed the benign nature of the lesion

Both adenosis and well differentiated prostate adenocancer are located in the transition zone, display small acinar proliferation and intraluminal crystalloids (5). The two most important distinguishing features that favour adenosis are the lack of significant cytological atypia and the presence of basal cells that may be patchy and can be demonstrated by immunohistochemistry for high molecular-weight cytokeratin (34ßE12) or p63. Prostatic adenocarcinoma, on the other hand, typically shows prominent nuclear atypia, lacks basal cells, and generally is negative for basal cell markers. AMACR is an enzyme that has increased expression and activity in the majority of prostatic carcinomas. Due to this reason, it is widely used as a biomarker of malignancy in prostate biopsies. However it is important to note that AMACR can also be focally expressed in 10\% of adenosis and can even diffusely be positive in $7.5 \%$ of cases.

Adenosis is not considered as a precursor lesion to malignancy. There is no substantial proof to establish a link between adenosis and prostatic carcinoma (4). That is the reason many pathologists prefer the term adenosis rather than naming as atypical adenomatous

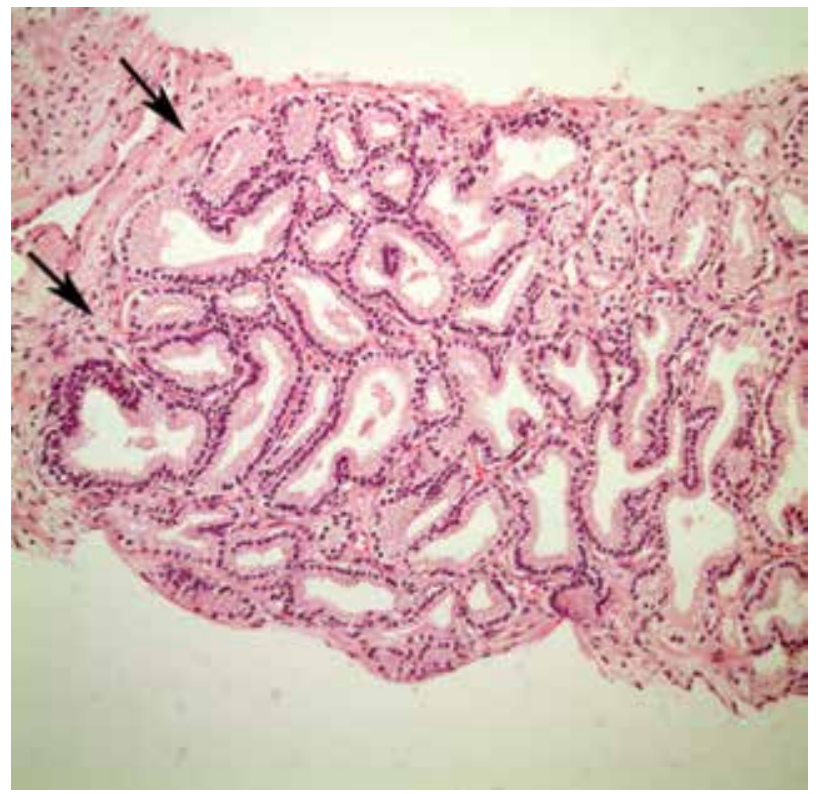

Figure 4 . The periphery of the focus sampled by the needle biopsy was rounded and well-delineated implicating an expansile growth rather than infiltrative (arrows). Another important feature observed was the presence of elongated glands with papillary infoldings and branching lumina similar to usual pattern of benign prostatic ducts. The diagnosis was adenosis. The other commonly used term for adenosis is: Atypical adenomatous hyperplasia

hyperplasia since designating these lesions as atypical may lead to unnecessary repeat biopsies. From a clinical perspective, adenosis should be considered as a benign lesion and patients are followed conservatively.

\section{References}

1. Helpap B. The biological significance of atypical hyperplasia of the prostate. Virchows Arch A Pathol Anat Histol 1980;387:307-317.

2. Gaudin $\mathrm{PB}$, Epstein Jl. Adenosis of the prostate. Histologic features in transurethral resection specimens. Am J Surg Pathol 1994;18:863-870.

3. Young $R H$, Srigley JR, Amin MB, et al.: Tumors of the prostate gland, seminal vesicles, male urethra and penis. Atlas of Tumor Pathology, 3rd Series, Fascicle 28, AFIP, 2000.

4. Epstein JI, Netto GJ. Mimickers of adenocarcnoma of the prostate. In: Epstein II and Netto GJ (ed.s). Biopsy Interpretation of Prostate. 4th edition, LWW, Philadelphia, 2008, p 105-156.

5. Bostwick DG, Srigley J, Grignon D, Maksem J, Humphrey P, van der Kwast TH, Bose D, Harrison J, Young RH. Atypical adenomatous hyperplasia of the prostate: morphologic criteria for its distinction from well-differentiated carcinoma. Hum Pathol 1993;24:819-832. 